\title{
Managing Continuity and Change for Strategic Performance
}

\author{
Sushil
}

Received: 3 September 2014 / Accepted: 4 September 2014/Published online: 11 September 2014

(C) Global Institute of Flexible Systems Management 2014

Strategic management literature has addressed the issues of both continuity and change in diverse shades and at different priorities. Initially, the emphasis has been laid down on highlighting the significance of continuity in terms of identity, stability, longevity, and incrementalism. However, in later part, the prime focus shifted to strategic change and transformation and various approaches such as restructuring, reengineering and reinventing gained prominence. Off late, it has been realized that the issues of continuity and change cannot be treated in a partial manner; any theory of change would be incomplete without addressing continuity of an organization. In the organizational context as well, management of continuity received attention by institutional theory, whereas later on neo-institutional theory treated change along with continuity in organizations. A discourse on continuity-change debate can be seen in previous editorials (Sushil 2013a, b). This brings out the fact that the continuity and change lie on a continuum and the boundary line between the two is very thin. The continuity and change can be formulated as a fuzzy set and are intermingled with each other in an inseparable manner.

Though a lot of endorsement of treating continuity and change together could be witnessed in the works of leading strategic and organizational thinkers, the literature has been lacking on how to implement or manage this paradox strategically. Flowing stream strategy (Sushil 2012a, b, 2014a) has provided framework and process of strategy formulation and execution by treating both continuity and change side by side. It provides strategic channels to mix

Sushil $(\square)$

Department of Management Studies, Indian Institute of

Technology Delhi, Vishwakarma Bhawan, Shaheed Jeet Singh

Marg, New Delhi 110016, India

e-mail: profsushil@gmail.com; sushil@dms.iitd.ac.in continuity and change at different levels of strategic flexibility, such as divert, shift, partition, and integrate.

Another central concern of strategic management has been to effectively manage strategic performance. The performance measurement and management has almost emerged as a separate body of knowledge to provide frameworks for managing strategic performance. In the earlier part of this body of knowledge, the focus has largely been on the financial performance of the enterprise and restricted to financial and managerial accounting models. Later, the non-financial measures have also been considered; first for the enterprise and then for the stakeholders (Sushil 2013c, 2014b). Some prominent frameworks that have been dealing with strategic performance in a more integrated manner are balanced scorecard, performance prism, triple bottom line, and flexible strategy game-card, among others.

The two strands of the literature, i.e. managing continuity and change on one hand, and strategic performance on the other, need to be aligned together. Strategic crystal (Sushil 2012a) treats the two planes in a single framework. On the plane of organizational reality, it takes the interaction of continuity and change forces. The other plane of strategic performance constitutes the interplay of enterprise as well as customer factors of performance. The two planes are aligned to each other by strategy formulation and execution. This framework has been used as the foundation for integrating strategic interventions with performance in the form of flexible strategy game-card, as outlined in previous editorials (Sushil 2010a, 2011).

Some notable strategies of managing continuity and change for higher strategic performance are cannibalization, blue ocean strategy, restructuring, offering solutions, and going green. For example, Microsoft could manage to retain its market share in operating systems market by 
cannibalizing its own leading platform DoS by Windows, a graphic user interface. It maintained the continuity of customer base by changing the technology and thereby managed to retain its market leadership. Blue ocean strategy emerged as a shift strategy of discontinuous change in creating a new market space for sudden and dramatic growth. Low cost airlines, such as South-West Airlines in US and many others in Indian context have exhibited unprecedented strategic performance by this route. Restructuring by partitioning continuity and change at different planes has also been practiced by many organizations to address both the survival and growth in uncertain market dynamics, as can be witnessed in mega mergers in steel and oil industries. Integrating the forces of continuity and change upfront is practiced in offering solutions for companies such as IBM to maintain the fulfilment of the similar customer needs but in a changed manner and thereby improving strategic performance of the enterprise as well as its stakeholders. Going green also maintains continuity of business, but at the same time changing by incorporating the environmental and sustainability considerations along with economic ones. This strategy has been used by many organizations including the retail leader, Walmart to enhance its market image.

In each of the above mentioned strategies, we can observe a clear delineation of managing continuity and change in different forms in order to address some or other dimension of strategic performance. Continuity and change form one of the multiple strategic paradoxes to be managed through strategic flexibility. Some other strategic paradoxes are globalization and localization, centralization and decentralization, and organic and inorganic growth. It requires a comprehensive framework to handle each of the strategic paradox and relate it with the strategic performance of the enterprise as well as its stakeholders, in the form of a star model (Sushil 2010b).

\section{References}

Sushil. (2010a). Flexible strategy game-card. Global Journal of Flexible Systems Management, 11(1\&2), iii-iv.

Sushil. (2010b). Star model of sustainable enterprise. Global Journal of Flexible Systems Management, 11(4), iii.

Sushil. (2011). Implementing flexible strategy game-card. Global Journal of Flexible Systems Management, 12(3\&4), iii.

Sushil. (2012a). Making flowing stream strategy work. Global Journal of Flexible Systems Management, 13(1), 25-40.

Sushil. (2012b). Business planning: The flowing stream strategy way. Global Journal of Flexible Systems Management, 13(4), $177-178$.

Sushil. (2013a). Is continuity a static frame of reference? Global Journal of Flexible Systems Management, 14(2), 67-68.

Sushil. (2013b). Does continuous change imply continuity? Global Journal of Flexible Systems Management, 14(3), 123-124.

Sushil. (2013c). Can flexibility be practiced in an isolated manner? Global Journal of Flexible Systems Management, 14(4), 179-180.

Sushil. (2014a). Leadership for practicing flowing stream strategy. Global Journal of Flexible Systems Management, 15(2), 89-90.

Sushil. (2014b). Duality of enterprise and stakeholders on flexibility front. Global Journal of Flexible Systems Management, 15(3), 179-180. 